УAK 1:316

ББК 60.01

DOI 10.22394/1682-2358-2018-4-95-102

E.I. Repina, postgraduate student of the Department of Public Relations and Advertising, Ulyanovsk State University

\section{SOCIAL RATIONALITY AS A SOCIOLOGICAL CATEGORY: THEORETICAL AND METHODOLOGICAL ANALYSIS}

The article presents theoretical and methodological analysis of the concept of social rationality. The main approaches to the rationality as an aspect of socio-cultural reality are described. Some implications of the term used in sociological and philosophical literature are revealed. The issue of the relevance of the study of rationality as a modern cultural value is touched upon.

Key words and word-combinations: social rationality, rationality of consciousness and behavior, rationalization.
Е.И. Репина, аспирант кафедри связей с общественностью и рекламь Ульяновского государственного университета (email: janeponomareva@bk.ru)

\section{СОЦИААЬНАЯ}

РАЦИОНААЬНОСТЬ КАК СОЦИО ООГИЕСКАЯ КАТЕГОРИЯ: ТЕОРЕТИКОМЕТОАОАОГИЧЕСКИЙ АНААИЗ

Аннотация. Проведен теоретико-методологический анализ понятия «социальная рациональность». Описаны основные подходы к представлению рациональности как аспекта социокультурной реальности. Выявлены косвенные импликации данного термина, используемые в социологической и философской литературе. Затронут вопрос актуальности изучения рациональности в качестве современной культурной ценности.

Ключевые слова и словосочетания: социальная рациональность, рациональность сознания и поведения, рационализация.

$\mathrm{P}$ ационацьность - многоаспектный, многофункциональный феномен, исследование которого приобретает особую значимость в связи с глобальными проџессами. В современном мироустройстве развитие социума, его усложнение связывается с рационализацией общественной жизни, выступающей оАним из факторов социокультурных изменений. Утверждение рациональности 
как ценности современной культуры - результат социальной модернизации, сопровождающейся урбанизацией, бюрократизацией, интенсификацией социальных связей, ростом значимости формального, прагматического, увеличением темпорацьности, быстротечности повсеАневной жкизни.

Исследовательский интерес к проблеме практической рациональности в современном обществе обусловлен ее универсальным характером. Она пропитывает «ткань» жкизнедеятельности человека и общества: ращионализирует обмасти экономики, науки, политики, культуры; совершенствует «человека современности», способствуя развитию таких качеств, как оперативность мысли, самокритичность, рефлексивность в проблемных ситуациях; благоприятствует становлению рациональной рефлексивной культуры.

Анализ работ, посвященных изучению раџиональности сознания и поведения мюдей, показац, что Аля разработки данной темы сложилась определенная теоретико-методологическая база. Понятие «раџионацьность» как принџипиально важная составляющая входит в структуру ряда философских конџепџий, кантианской, позитивистской и других направленностей. Активно изучаемая в зарубежной и отечественной философской митературе, в социологической теории категория «рационацьность» разрабатывается значительно меньше. НеАостаток эмпирической операционацизации понятия также обуславливает проблемное поле исследования. Вероятно, максимацьно понять проблематику раџиональности возможно при уяснении как соџиологических оснований исследования рациональности, так и философских истоков данного феномена.

В самом общем виде термин «рациональность» (от мат. Ratio - разум) означает целесообразность, упорядоченность, могичность, соразмерность. В некоторых митературных источниках содержание понятия связывается с эффективностью целедостижения [1, с. 144], соответствием поставленных целей и средств их Аостижения [2], обоснованностью выбора среАств деятельности с учетом средовых факторов [3], особой установкой сознательной Аеятельности, Аля которой характерны могическая упорядоченность, целесообразность и системность [4, с. 11], а также свобода от какого бы то ни бымо принуждения [5, с. 426].

В социологии рациональность рассматривается прежде всего в значении «соџиальной раџионацьности», в отношении которой также сушествует теоретический плюрализм. Соџиальная раџиональность интерпретируется как тип ращионацьности: 1) выражкающий совокупность стандартов группового поведения, направленного на реализаџию соџиально значимых Аця данного социума целей [6, с. 69] ; 2) связанный, во-первых, с познавательно-преобразующей деятельностью индивидов и соџиальных групп, во-вторых, с функционированием социальных систем, их внутренней раџиональностью, проявмяющейся в структурной организаџии, функции саморегуляџии, соџиальных взаимодействиях с индивидами и соџиальными институтами [7, с. 3] .

Можно выделить четыре основных направления в определении сущности понятия «рационацьность». Первое направление объясняет раџионацьность через взаимосвязь с разумом и рассудком - Авумя основными типами мысмящего сознания мичности (по способу умственной деятельности). О рациональности и разумности как одном из ее аспектов размышияли представители 
фимософской (Сократ, Р. Аекарт, Т. Гоббс, Аж. Аокк, И. Кант, М. Хайдеггер и лр.) и социологической (М. Вебер, Э. Фромм, К. Поппер, Т. Адорно и Ар.) мысли.

Под рациональностью в этом кАюче понимаются «некоторые общезначимые проявления человеческого разума, обусловленные культурно, исторически и т.А.» [8, с. 104]. В рамках феноменологии рациональность рассматривается через призму повседневности. Согласно Б. Вальденфельсу, «рацио» - это «то, что воплощается в смысловые, правильные, регуцярно повторяющиеся, рассудочно-прозрачные взаимосвязи, которые существуют в различных помях и стилях раџиональности» [9, с. 41]. Продолжатели феноменологической траАиции выявляют взаимосвязь раџиональности с рефлексивным мышлением. ПоА этим углом зрения А.О. Труфанов трактует рациональность как совокупность рефлексивных содержаний соџиальной реальности, получаемых в процессе понимания себя и других в социальном мире [10]. Раџиональность как постоянная апемляџия к доводам разума представмяет определенный интерес как для преАставителей западноевропейской фимософии (К. Поппер), так и для современных социальных философов. В.С. Швырев очень точно различает сознание, вплетенное в ткань реальной жкизнедеятельности мюдей в качестве ее идеального плана, и сознание, выделенное из этой жизнедеятельности и ставшее предметом рефмексии. Раџиональность как опредекенный тип работы сознания включает оба этих смысла и представмяет собой раџиональное отношение к реальности как совокупности внешнего, окружающего, и внутреннего, ментального, мира человека [11, с. 105].

Нередко «разум» и «рассудок» употребцяются в китературе как понятия, синонимичные мышлению, интемлекту. В разработке теории раџиональности принџипиально различение этих феноменов. Э. Фромм разводит "разумную» раџиональность как интелмектуально ориентированную деятельность, направменную на постижение окружающего мира и формирование истинных знаний о нем, и «рассудочную» раџиональность, выступающую инструментом Аля достижения успеха, манипулирующую «миром вещей» посреАством мышмения [12, с. 325].

Иногда раџиональность отождествляется с расчетливостью. В этом случае анализ раџиональности возможен через призму теории раџионального выбора. Авторы данной конџепции (Р. Комлинз, Аж. Коулмен, Й. Элстер и др.) допускают, что раџионально рассчитанные действия индивидов, предполагающие обзор всех возможных поведенческих альтернатив и их последствий, позволяют добиться максимальной выгоды при минимальных физических и интемлектуальных затратах [13, с. 156].

Трактовка рациональности в контексте теории рационального выбора не сводится только к постановке цемей, мотивированных эгоистическими побуждениями, и извлечению выгоды из мюбой сложившейся ситуации. Рациональным может быть выбор как субъективно-значимой, так и социально-полезной цели [14, с. 562]. И.Т. Касавин уточняет, что не всякая поставленная цель считается раџиональной, а только та, которая способствует соџиальному прогрессу. Цемь нерациональна и ее достижение не требует раџионального поА- 
хода, если она не имеет реацьного отношения к прогрессу, и иррациональна, если она противоречит ему [15, с. 64].

Точный расчет и мобилизация наиболее эффективных средств достижения практической цели межат в основе интемлектуацизации, о которой писал М. Вебер. В результате рационацизации, «расколдования» мира таинственные, не подАающиеся учету силы сошли на нет. Успех целедостижения стал возможным благодаря применению различного рода технологий. «Больше не нужно прибегать к магическим средствам, чтобы склонить на свою сторону или подчинить себе духов, как это делал дикарь, Аля которого существовали подобные таинственные силы. Теперь все это делается с помощью технических средств и расчета. Вот это и есть интемлектуализация», - полагает ученый M. Вебер [5, с. 713].

НереАко «рациональное» объясняется через взаимосвязь с «иррациональным» и, в меньшей степени, «нерациональным». Разцичают два наиболее распространенных смысла «иррационального». Прежде всего, этим термином обозначают то, что непостижимо Аля раџионального сознания, что не подлежит раџиональной критике. Иррациональными считаются явления, которые немыслимы в виде рационализированного объекта, поскольку они не обладают «внутренней

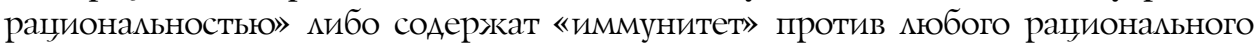
проявления. К сфере иррационального относится также то, что выходит за рамки данной рациональной системы мибо не соответствует ее критериям [16] .

Некоторые исследователи считают нецелесообразным понимать под раци-

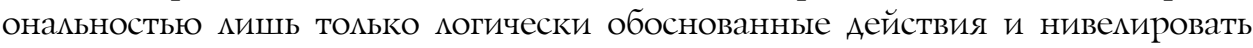
роль нерациональных и иррациональных компонентов. Рациональность, по их мнению, охватывает горазАо большее, чем только сушествующее в пределах разума. Как полагает философ А.А. Новиков, «рациональность - как Аействительно разумное человеческое развитие - не только продуманный, рассчитанно сбалансированный, но, прежде всего, нравственный путь, когда Аолг, альтруизм, милосердие, строго говоря, нерациональные факторы, не вытесняются и знание не подавцяет совести» [17, с. 49].

Проблема взаимосвязи раџиональности и иррациональности присутствует в соџиологических воззрениях М. Вебера. В этом вопросе он придерживается принципа релятивизма, на примере рационализации различных жкизненных областей демонстрируя, что мюбое явление может быть оџенено одновременно и как рациональное, и как иррациональное. Вебер писал: «...в рамках каждой подобной отрасли “рационализация” может быть проведена с самых разцичных позиций при размичной целенаправленности, причем то, что с оАной точки зрения явцяется "рациональным", с другой может казаться "ирраџионацьным”. Поэтому во всех культурах существоваци самые различные рационализации в самых размичных сферах» [5, с. 55] .

Существует мнение, что «рационацьное» и «иррациональное» взаимодействуют в форме перетекания одного состояния в Аругое. Иной вопрос - насколько сознателен этот процесс перехода от рациональности к иррациональности и наоборот. Разработанная М. Вебером конструкция целерационального Аействия служит в соџиологии идеальным типом Аля оџенки степени ирраџи- 
ональности социального действия. Посредством целерациональности реальное, обусловленное разцичными иррациональными факторами (аффектами, заблуждениями, эмоџиональными состояниями), поведение обособляется от чисто рационально сконструированного [5, с. 55, 497, 605]. На взгляА М. Вебера, нормативная рациональность всегда иррационацьна, поскольку абсолютизирует роль ценностных ориентиров (представления о Аолге, чести, достоинстве, красоте, мюбви, Аоброте, религиозные убеждения и морахьные принципы), которым следует индивиА в своей деятельности, невзирая на возможные последствия совершаемых поА их влиянием действий [5, с. 629] .

Противопоставление «рациональности» и «нерациональности» в основном связывается с нацичием или отсутствием у индивида определенной установки на рациональную деятельность, рациональное отношение к миру. По мнению В.С. Швырева, такая установка предполагает «специальные усиция сознания» индивида по анацизу соразмерности своей позиции реальному положению дел $[11$, c. 112$]$.

Когда речь идет о рациональности как системе замкнутых и самодостаточных правиц, норм, стандартов, эталонов, принятых и общезначимых в рамках конкретного общества Аля Аостижения социально осмысленных целей [16] , «рациональное» употребцяется как синоним «формального».

Импульс к подобного рода утверждениям дают размышления М. Вебера о формальной рациональности. Этот сложкный соџиальный феномен рассматривается в значении целеполагания как проџесса постановки одной или нескольких целей и их Аостижения наиболее рентабельными среАствами. Расширение и дополнение этого концепта наблюдается в теории макдональдизации Аж. Ритцера. Социолог «измеряет» формальную рациональность в соответствии с четырьмя переменными - эффективностью, калькуляцией, предсказуемостью и контролем [14, с. 188]. Исходные элементы формальной раџиональности - поиск оптимального способа достижения цели, калькуляџия затрат на ее реализаџию, принятие строгих правиц деятельности и контроль за их соблюдением - нашии также отражение в теории играизации С.А. Кравченко.

Формальная рациональность, формирующая ту самую «железную киетку» - социум, в котором инаивиА, отрешенный от религиозных и моральных ценностей, нравственных идеалов, подвергается возрастающей бюрократизации, жесткому экономическому регулированию и тотальной рационализации всех сфер общественной жизни, выступала объектом критики многих соџиологов (К. Мангейм, Г. Маркузе, М. Хоркхаймер, Т. ААорно и ар.). Их воззрения мегли в основу направцения, утверждающего существование «ирраџионацьной» ими «дегуманистической» рациональности. Подобного рода раџионацьность сопряжена с Аоминированием, властвованием одних мюдей (или соџиальных групп) наА Аругими. Она Аегуманизирует человеческие отношения, приводит к отрицанию традиционных ценностей, обезличиванию, превращению мичностей в абстрактные типажи, обесцениванию Ауховного начала в человеке, становится реацьной угрозой существованию гармоничного гражданского общества [14, с. 327, 489, 490] .

Помимо формальной и построенной на ее критике иррациональной рациональности в поле исследовательского интереса находится следующее: 
- коммуникативная рациональность, исключающая всякого рода принужАение, отношения экспиуатации и доминирования (Ю. Хабермас);

- когнитивная раџиональность, обусловленная чисто познавательными ценностями; инструментальная, основанная на эффективности планирования и применения средств с ориентацией на поставменные цели; интегративная как объединение индивидуального и комлективных усилий Аля Аостижения цели; конститутивная, обеспечивающая внутреннюю самотождественность индивидов с опорой на главенствующую систему ценностей (Т. Парсонс);

- западная рациональность, Аля которой характерна ориентация на достижение индивидуальных целей, более высокая оџенка частной инициативы, меньшее внимание к духовно-нравственным качествам индивида и культурным традициям общества, и восточная рациональность, отличающаяся объединяющим характером и ориентацией на интересы, эмоции, чувства индивидов (Р.Т. Убайдуммаева);

- повседневная раџиональность или рациональность обыденной жкизни, воплощающаяся в трех формах: просачивающейся, поднимающейся и сплавмяющейся рациональности (Б. Вальденфельс);

- ограниченная, связанная с неопределенностью, и полная, предпомагающая нацичие возможных ацьтернатив на стадии принятия решения (В.В. Попов, Б.С. Щеглов);

- закрытая и открытая ращионацьность, о которой речь пойдет далее (В.С. Швырев), и Аругие.

Практически все типы рациональности тем или иным образом связаны Аруг с Аругом, посколыку направцяются социальными действиями, крайне реАко ориентированными только на один определенный тип раџиональности. Некоторые из перечисленных выше явцяются созданными дия научных исслеАований «понятийно чистыми типами» [5, с. 630], к которым в большей или меньшей степени приближены реальные соџиальные действия индивидов.

В общем виде тип ращиональности преАставцяет собой модель Аействия, которая облекается индивидом в определенную форму с конкретным содержательным наполнением. Р.Т. Убайдумлаева отождествцяет тип раџиональности с типом мировоззрения ввиду их сходства как систем субъективных взглядов индивидов на мир и свое место в нем [18]. Рациональность в таком ключе обусловливает выбор жизненных позиџий, убежАений, принципов в Аостижении целей, могику смыслонаделения. Как и мировоззрение, она содержит элемент субъективности, единоличности. Индивидуальная практическая рациональность преАполагает, что то, что Аля одного индивида явцяется разумным, уместным, Аля Аругого - спорным, неявным, неправицьным.

Выводы некоторых ученых в отношении рационацьности довольно категоричны. Критический настрой Н. Решера принимает форму негативизма, отриџания идеи рациональности как таковой. Ученый воспринимает рациональность как «пустое понятие», что превращает ее из необходимой культурной ценности в «заблуждение и обман» [19, с. 35]. В.Н. Порус описывает рациональность в метафоричной форме в качестве «волнующей загадки», указывая

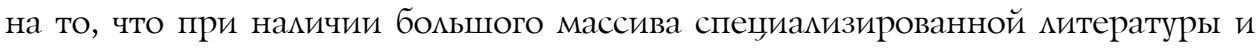

100 Bulletin of the Volga Region Institute of Administration • 2018. Vol. 18. № 4 
не утихающих научных споров, «нет ни общепринятого определения понятия “рациональность”, ни согласия в том, что считать проблемой, связанной с этим понятием» [16]. Все это, в свою очереАь, осложняет распознавание и постановку проблем исследований, посвященных изучению рациональности.

Наиболее близка авторскому пониманию позиция В.С. Швырева, который рассматривает рациональность как определенный тип отношения к миру, способ его «вписывания» в мир. ЗАесь необходимо добавить, что рациональное отношение к реальности предусматривает не столько проявление "мужества пользоваться собственным умом» [20, с. 27], сколько формирование определенной рациональной культуры, предполагающей адекватное понимание проблемной ситуации, критико-рефлексивную установку на соразмерность поведения индивида и реальностей мира, стремление к эффективности, успешности деятельности, сознательное управление поведением, поиск оптимального способа достижения цели и т.А. [11, с. 112]. Такое понимание рационацьности межит в основе разведения «открытой», гибкой, способной к усовершенствованию, и «закрытой», строго конвенционацьной рациональности $[11$, с. 111$]$.

Согласно авторскому видению проблемы, в современном обществе Аоминирует гибридный тип рациональности. Гибридность означает сочетание размичных типов раџиональности, находящееся в процессуальном контексте как переход, перетекание одного типа рациональности, одного типа отношения к реальности в Аругой на основе анализа исходных позиџий путем продумывания определенной стратегии поведения, подбора среАств достижения цели.

Гибридная рациональность - это та форма раџиональности, которая считается индивидом наиболее эффективной, приемлемой, продуктивной в Аанной ситуации с учетом имеющихся, а не иных, условий, возможностей человеческой субъективности. Гибридный тип раџиональности как некий уникальный принцип культуры выражает пластичное, динамичное отношение человека к реацьности, его готовность к конструктивному взаимодействию с Аругими соџиальными субъектами, способность критически осмысливать исходные идейные позиции и корректировать их в зависимости от ситуации, в которую он погружен.

В современном социуме рациональность, выражкающаяся в практичном, прагматичном отношении к миру, становится востребованной культурной ценностью, существующей наряАу со справедиивостью, честностью, альтруизмом, муаростью и Аругими ценностями. Рациональное сознание открывает реальность в разцичных ракурсах и проекциях, способствует внутренней самодисциплине индивида, стабилизирует общественные отношения, выступая фактором сощиамьного порядка.

\section{Библиографический список}

1. Джери Д., Джери Дж. Большой толковый социологический словарь: в 2 т. / пер. с англ. Н.Н. Марчук. М., 1999. Т. 2.

2. Давыдов Ю.Н. М. Вебер и проблема интерпретации рациональности // Вопросы социологии. 1996. Вып. 6. С. 71-77. 
3. Култысин В.П. Теория рационального выбора - возникновение и современное состояние // Социологические исследования. 2004. № 1. С. 27-36.

4. Карташев Д.Е. Рациональность как социальный феномен: автореф. дис. ... канд. филос. наук. Саранск, 2009.

5. Вебер М. Избранные произведения / пер. с нем., сост., общ. ред. и послесл. Ю.Н. Давыдова; предисл. П.П. Гайденко. М., 1990.

6. Ракитов А.И. Рациональность и теоретическое познание // Вопросы философии. 1982. № 11. C. $68-81$.

7. Сивиринов Б.С. Социальная рациональность как компонент социальной перспективы // Социологические исследования. 2003. № 4. С. 3-12.

8. Анкин Д.В. Рациональность и рационализация в философском дискурсе // Эпистемы. 2004. Вып. 3: Язык. Дискурс. Текст: материалы межвузовского семинара: альманах. С. 102-116.

9. Вальденфельс Б. Повседневность как плавильный тигль рациональности / сост., общ. ред. и предисл. В.В. Винокурова, А.Ф. Филиппова. М., 1991.

10. Труфанов Д.О. «Рациональность обыденной жизни» в контексте постнеклассической социологической теории рациональности // Актуальные вопросы экономики, права, психологии, педагогики и социологии в глобальном мире: сборник научных статей по итогам международной научно-практической конференции. Волгоград, 2012. URL: https://trufanov.wordpress. com/2012/04/06/everyday-life/

11. Швырев В.С. Рациональность в современной культуре // Общественные науки и современность. 1997. № 1. С. 105-116.

12. Фромм Э. Здоровое общество // Психоанализ и культура: избранные труды Карен Хорни и Эриха Фромма. М., 1995.

13. Ритцер Дж. Современные социологические теории. 5-е изд. М.; СПб, 2002.

14. Кравченко С.А. Социология: парадигмы через призму социологического воображения. M., 2007.

15. Касавин И.Т. О социальном содержании понятия «рациональность» // Философские науки. 1985. № 6. С. 64-65

16. Порус В.Н. Рациональность. Наука. Культура. М., 2002.

17. Новиков А.А. Рациональность в ее истоках и утратах // Вопросы философии. 1995. № 5. C. $48-60$.

18. Убайдуллаева Р.T. О социальной рациональности и ее типах // Социологические исследования. 2013. № 11. С. 10-17.

19. Решер Н. Границы когнитивного релятивизма // Вопросы философии. 1995. № 4. С. 35-55.

20. Кант И. Ответ на вопрос: что такое Просвещение? // Соч.: в 6 т. М., 1966. Т. 6. 